\title{
VOLUMETRIC ERROR COMPENSATION IN FIVE-AXIS CNC MACHINING CENTER THROUGH KINEMATICS MODELING OF GEOMETRIC ERROR
}

\author{
Pooyan Vahidi Pashaki ${ }^{1 *}$, Milad Pouya² \\ 1 School of Mechanical Engineering, Islamic Azad University, Science and Research Branch of Tehran (Central), \\ Hesarak, Tehran, Iran. *Corresponding author e-mail: pooyan.vahidi66@gmail.com \\ 2 School of Mechanical Engineering, University of Guilan, Rasht, Iran, e-mail: miladpouya5@gmail.com
}

Received: 2016.04.13

Accepted: 2016.05.16

Published: 2016.06.10

\begin{abstract}
Accuracy of a five-axis CNC machine tool is affected by a vast number of error sources. This paper investigates volumetric error modeling and its compensation to the basis for creation of new tool path for improvement of work pieces accuracy. The volumetric error model of a five-axis machine tool with the configuration RTTTR (tilting head B-axis and rotary table in work piece side $\mathrm{A}^{\prime}$ ) was set up taking into consideration rigid body kinematics and homogeneous transformation matrix, in which 37 error components are included. Volumetric error comprises 37 error components that can separately reduce geometrical and dimensional accuracy of work pieces. The machining accuracy of work piece is guaranteed due to the position of the cutting tool center point (TCP) relative to the work piece. The cutting tool is deviated from its ideal position relative to the work piece and machining error is experienced. For compensation process detection of the present tool path and analysis of the RTTTR fiveaxis CNC machine tools geometrical error, translating current position of component to compensated positions using the Kinematics error model, converting newly created component to new tool paths using the compensation algorithms and finally editing old G-codes using G-code generator algorithm have been employed.
\end{abstract}

Keywords: kinematics error modeling, compensation, volumetric error, CNC machine tool

\section{INTRODUCTION}

Specifically, ample number of researches has been completed in the past to investigate and compensate for the errors in three-axis machine tools. However, five-axis machine tools have not been widely studied due to its complex machine structure. To this end, the error compensation of fiveaxis machine tools will be discussed. The five-axis machine tools are progressively renowned for developing the demand for machining the work piece with growing geometric complexity along with high accuracy [1] and have been given more and more consideration, due to the special advantages in manufacturing. In comparison with threeaxis machine tools, they have many advantages, which includes better versatility and flexibility, higher machining efficiency, as well as accuracy. Most common five-axis machine tools comprises three translation axis $(\mathrm{T})$ and two rotating axis (R). According to machine configuration, three major types of five-axis machine tools are widely used in industry: (a) RRTTT type - two rotational axes attached to the machine spindle and three translational axes for the movements of table and spindle housing; (b) TTTRR type - three translational axes ( $\mathrm{x}, \mathrm{y}$, and $\mathrm{z}$ axis) for the movements of table and spindle housing, and two rotational axes attached to the table; (c) RTTTR type - one rotational axis attached to machine spindle, three translational axes ( $\mathrm{x}, \mathrm{y}$, and $\mathrm{z}$ axis) for the movements of table and spindle housing, and one rotational axis attached to the table. The volumetric errors of five-axis machine tools include three 
total position errors and two rotation errors. In this article, five-axis machine tools with RTTTR configuration was evaluated for error kinematic chain modeling with tilting head and rotary table. The machine errors were found to directly influence accuracy of the machined work piece, which has many types. Due to their different causes, dynamic as well as thermally induced errors differ from geometric errors, resulting in distinct error compensation strategies. This article only deals with geometric errors and their effects; thus the error compensation discussed below is within the scope of geometric errors. In general, the error compensation works in the following process: Error identification; Error measurement; Error compensation.

Ramesh et al. [2] reviewed related research on machine error and pointed out that geometric and kinematic errors serve as framework for the basic inaccuracy of a machine tool. Error synthesis method is an important error identification method for the machine tool, which is capable of obtaining the total error in terms of individual error components. The primary focus of this method is volumetric error modeling and compensation. Volumetric error modeling of the machine tool is generally taking into consideration rigid body kinematics, in which homogeneous transformation matrix (HTM) is used to represent the coordinate transformation between each rigid body frame with its reference coordinate system [1]. The Homogeneous Transformation Matrices (HTMs) in connection with the rigid body kinematics have been adopted extensively to derive the machine tool errors, due to the convenience of expressing machine tool deviations and simplicity in modelling the machine structure systematically [3-6]. According to the theory, a machine tool of several moving linkages in addition to a five-axis machine tool is formed; machine tool errors are as a result of linkage errors and motion errors [7]. Matrices usually helps to express different error sources in linear and rotary axes. With a sequential multiplication of these specified HTMs following the order of the kinematic chain, the method is able to determine the position and orientation of the tool with respect to the work piece. After the error sources are identified, the second step is conducted to evaluate them using certain measuring techniques. As suggested in the preceeding step, it is necessary to obtain the values of errors in order to calculate the machine accuracy. Thus various measurements are conducted to deal with different types of error sources. As soon as the errors are identified and determined, compensation is then needed for enhancing the accuracy of the machine tool. Much information can be obtained in the related field of volumetric error modeling of five-axis machine tools. Kiridena and Ferreira [1] presented an approach to mapping the effects of the positioning errors on the volumetric accuracy of a five-axis machine tool, based on the rigid body kinematics and D-H transformation matrix. Srivastava et al. [8] depicted an orderly technique for the improvement of geometrical and thermal errors in view of the kinematic analysis of machine structure. The presented method directly took into account the shape and joint transformations for inaccurate links and joints in place of using $\mathrm{D}-\mathrm{H}$ transformations.

Jha and Kumar [9] used a generalized volumetric error model of a five-axis machine based on D-H transformation matrix for geometric error compensation, which improved the quality of the CAM profile creation experiment. Lei and Hsu [10] reported another test ball measurement device that helps directly measure the overall position errors of a five-axis machine tool. The volumetric error modeling was conducted as a theoretical explanation based on rigid body kinematics and HTM. Several scholars [4, 11-14] analyzed the volumetric error synthesis model of a multi axis machine based on this method and revealed its effectiveness. Bohez et al. [15] proposed another approach to recognize and compensate all the systematic geometric errors of five-axis milling machines. The mathematical model was based on a first-order rigid body model of the machine tool with angular errors that can be identified independently of the translational errors. Previous literature indicate that most error modeling studies mainly aimed at error compensation and accuracy improvement of the machine tool. Regarding sensitivity analysis of machine tool error, Huang et al. [16] used error mapping function to analyze the source errors affecting the uncompensatable pose error for a three-DOF parallel kinematic machine. Hong et al. [17] examined the influence of position-dependent geometric errors of rotary axes on cone frustum machining test in the five-axis machine tool. Lee and Lin [18] investigated the effect of each assembly error term on volumetric error of a five-axis machine tool according to form-shaping theory. 
The above work acquired some positive results; although, more research needs to be conducted on compensation of the volumetric error of the five-axis machine, this paper will focus more on volumetric error modeling and its compensation of a five-axis machine tool. The findings observed are connected into the accuracy five-axis machine tool with the configuration of RTTTR for enhancement and production of accurate work pieces. The machining experiment will be conducted to test the compensation algorithm.

\section{KINEMATIC MODELS FOR GEOMETRIC ERROR IDENTFICATION}

\section{Geometric error definition for the rotary axis}

The vertical machining center examined in this paper has three linear axes with one rotation axis in tool side and another rotation axis in work piece side. The movement in all axes is controlled simultaneously. This configuration takes into consideration the control of position, like a three-axis machine tool, with the two additional rotational axes giving the additional advantage of controlling the orientation of the tool with respect to the work piece. The schematic diagram of five-axis machine tool used in this article is shown in Figure 1 , which has the tilting head and rotary table with

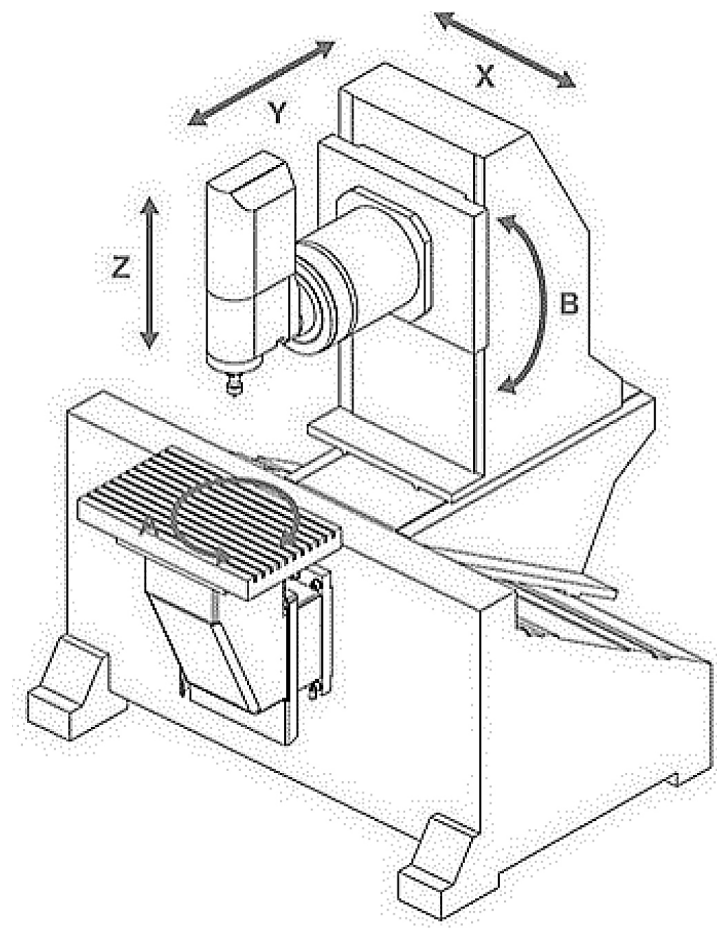

Fig. 1. Geometric error identification of a five-axis machine tool the configuration of RTTTR. The machine tool has three translational axes and two rotational axes, that is, $\mathrm{X}$-axis, Y-axis, Z-axis, $\mathrm{B}$-axis, and $\mathrm{A}^{\prime}$-axis, respectively. According to ISO 10791-1 the axis that carries work pieces shall be shown with prim as this configuration for $\mathrm{A}^{\prime}$-axis. The tool system is mounted on the B-axis and supported by the Zaxis. The work piece is mounted on the $\mathrm{A}^{\prime}$-axis.

Geometric errors in machine tools are a product of many factors, such as kinematic errors, thermo-mechanical errors, loads and load variations, dynamic forces, as well as motion control and control software. Geometric errors of the machine tool depend on the error motion of each axes and those between linear and rotational axes. From rigid body kinematics viewpoint, every linear and rotational axis has six geometric error components including one positioning error, two straightness errors, and three angular errors called pitch, yaw, and roll respectively, that are position dependent. Error motions of linear and rotational axes are as shown in Figure 2 [19].

Thus, the five-axis machine tool in Figure 1 has 30 position-dependent errors, which are shown in Table 1. Here, the linear error motion in $\mathrm{x}$ directions are $\mathrm{e}_{\mathrm{xx}}, \mathrm{e}_{\mathrm{yx}}$, and $\mathrm{e}_{\mathrm{zx}}$ where the subscript shows the error direction; also, the angular errors motion in $\mathrm{x}$ direction are $\mathrm{e}_{\mathrm{AX}}, \mathrm{e}_{\mathrm{BX}}$, and $\mathrm{e}_{\mathrm{CX}}$ where the subscript shows the rotation axis of angular motion. The values of linear motion coordi-

Table 1. Position-dependent errors of a five-axis machine tool

\begin{tabular}{|c|c|}
\hline Axis name & Error components \\
\hline X-axis & $e_{\mathrm{XX}}, \mathrm{e}_{\mathrm{YX}}, \mathrm{e}_{\mathrm{ZX}}, \mathrm{e}_{\mathrm{AX}}, \mathrm{e}_{\mathrm{BX}}, \mathrm{e}_{\mathrm{CX}}$ \\
\hline Y-axis & $\mathrm{e}_{\mathrm{XY}}, \mathrm{e}_{\mathrm{YY}}, \mathrm{e}_{\mathrm{ZY}}, \mathrm{e}_{\mathrm{AY}}, \mathrm{e}_{\mathrm{BY}}, \mathrm{e}_{\mathrm{CY}}$ \\
\hline Z-axis & $\mathrm{e}_{\mathrm{XZ}}, \mathrm{e}_{\mathrm{YZ}}, \mathrm{e}_{\mathrm{ZZ}}, \mathrm{e}_{\mathrm{AZ}}, \mathrm{e}_{\mathrm{BZ}}, \mathrm{e}_{\mathrm{CZ}}$ \\
\hline A-axis & $\begin{array}{l}\mathrm{e}_{\mathrm{XX}}(\alpha), \mathrm{e}_{\mathrm{YX}}(\alpha), \mathrm{e}_{\mathrm{ZX}}(\alpha), \\
\mathrm{e}_{\mathrm{AX}}(\alpha), \mathrm{e}_{\mathrm{BX}}(\alpha), \mathrm{e}_{\mathrm{CX}}(\alpha)\end{array}$ \\
\hline B-axis & $\begin{array}{l}\mathrm{e}_{\mathrm{XX}}(\beta), \mathrm{e}_{\mathrm{YX}}(\beta), \mathrm{e}_{\mathrm{ZX}}(\beta), \\
\mathrm{e}_{\mathrm{AX}}(\beta), \mathrm{e}_{\mathrm{BX}}(\beta), \mathrm{e}_{\mathrm{CX}}(\beta)\end{array}$ \\
\hline
\end{tabular}

Table 2. Position and orientation error parameters for a five-axis machine tool [21]

\begin{tabular}{|c|c|c|c|c|c|}
\hline $\mathrm{B}$-axis & X-axis & Y-axis & Z-axis & A-axis & $\begin{array}{c}(\mathrm{C} 1)- \\
\text {-spindle }\end{array}$ \\
\hline $\mathrm{E}_{\mathrm{XOB}}$ & $\mathrm{E}_{\mathrm{X} 0 \mathrm{X}}$ & - & - & - & $\mathrm{E}_{\mathrm{XO}(\mathrm{C} 1)}$ \\
\hline $\mathrm{E}_{\mathrm{YOB}}$ & - & $\mathrm{E}_{\mathrm{YOY}}$ & - & $\mathrm{E}_{\mathrm{YOA}}$ & $\mathrm{E}_{\mathrm{YO}(\mathrm{C} 1)}$ \\
\hline- & - & - & $\mathrm{E}_{\mathrm{Z} 0 \mathrm{Z}}$ & $\mathrm{E}_{\mathrm{ZOA}}$ & - \\
\hline $\mathrm{E}_{\mathrm{AOB}}$ & - & $\mathrm{E}_{\mathrm{AOY}}$ & $\mathrm{E}_{\mathrm{AOZ}}$ & $\mathrm{E}_{\mathrm{AOA}}$ & $\mathrm{E}_{\mathrm{AO}(\mathrm{C} 1)}$ \\
\hline $\mathrm{E}_{\mathrm{B} 0 \mathrm{~B}}$ & $\mathrm{E}_{\mathrm{BOX}}$ & - & $\mathrm{E}_{\mathrm{BOZ}}$ & $\mathrm{E}_{\mathrm{BOA}}$ & $\mathrm{E}_{\mathrm{B}(\mathrm{C} 1)}$ \\
\hline $\mathrm{E}_{\mathrm{COB}}$ & $\mathrm{E}_{\mathrm{COX}}$ & $\mathrm{E}_{\mathrm{COY}}$ & - & $\mathrm{E}_{\mathrm{COA}}$ & - \\
\hline
\end{tabular}



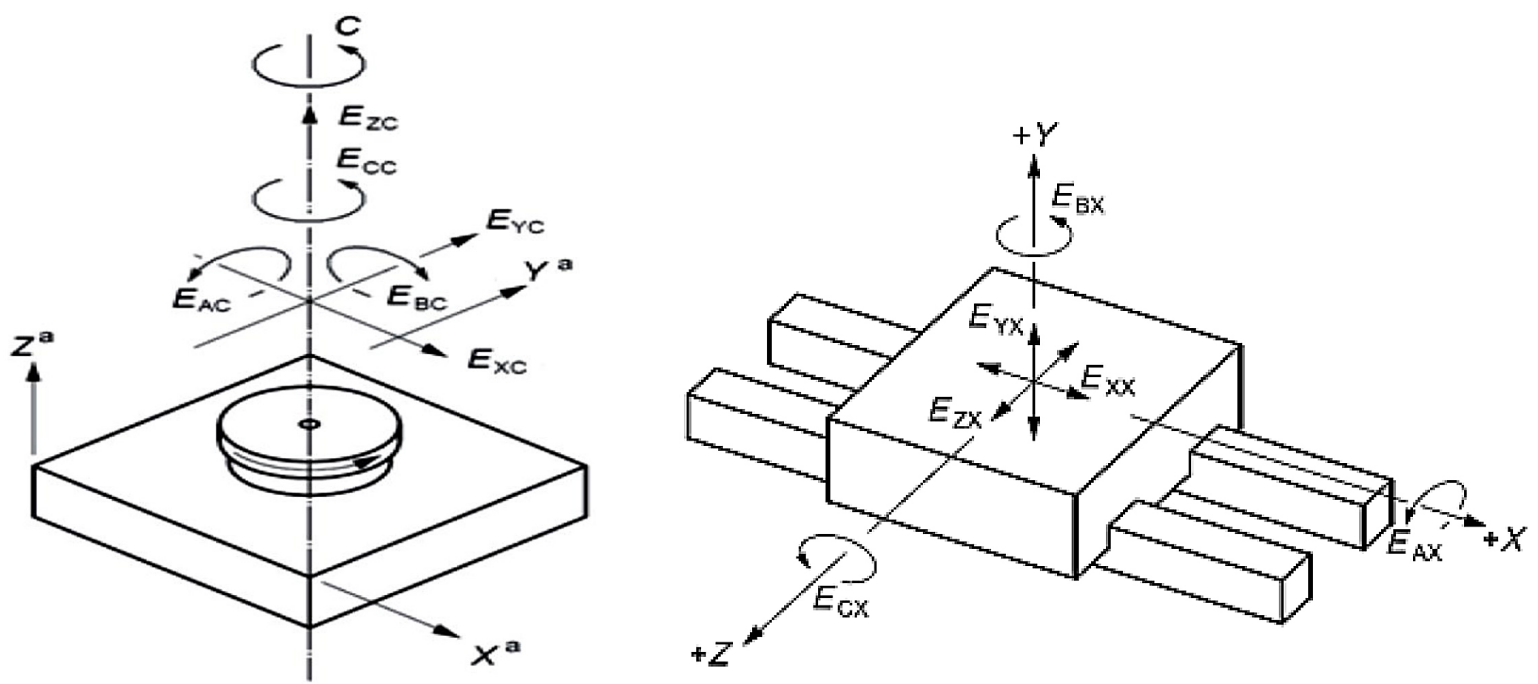

Fig. 2. Angular and linear error motions of a linear and rotary axis [19]

nate of $\mathrm{X}$-axis, $\mathrm{Y}$-axis, and $\mathrm{Z}$-axis are $\mathrm{x}, \mathrm{y}$, and $\mathrm{z}$, respectively. The rotation angles of $\mathrm{A}^{\prime}$-axis and $\mathrm{B}$-axis are $\alpha$ and $\beta$, respectively. There are also position-independent errors in the machine tool, which are the location errors of an axis represented as an error from the nominal position and orientation of this axis in the machine coordinate system [20]. The reference straight line of a linear axis of motion represents its direction with two orientations $[2,18]$. Location errors of a linear axis represent orientations of its reference straight line in the reference coordinate system (known as the machine tool coordinate system [2, 21, 22]). Generally, a translational axis with regard to the nominal position has three location errors, that is, one zero position error and two orientation errors. It must be emphasized that location errors represent "average" positions or orientations, since, in principle, all zero positions of linear and rotary axes can be set to zero when checking the geometric accuracy of the machine tool. An example of location errors of Z-axis is shown in Figure 3. rotational axis in view of the nominal position which has five location errors, $\mathrm{v}_{\mathrm{iz}}$; two position errors, two orientation errors, and one zero angular position error. However, due to selection of reference position and coordinate system, most of the location errors can be disregarded in real error modeling, leaving behind only orientation errors, like squareness errors here. In this research, the reference direction of the corresponding axis of each coordinate system is chosen as the real motion direction of $\mathrm{X}$-axis; hence $\mathrm{X}$-axis has no location errors. The plane through $\mathrm{X}$-axis and $\mathrm{Z}$ axis is chosen as reference plane, leaving $Z$-axis with one squareness error $\left(\mathrm{E}_{\mathrm{xOZ}}\right)$, and $\mathrm{Y}$-axis with

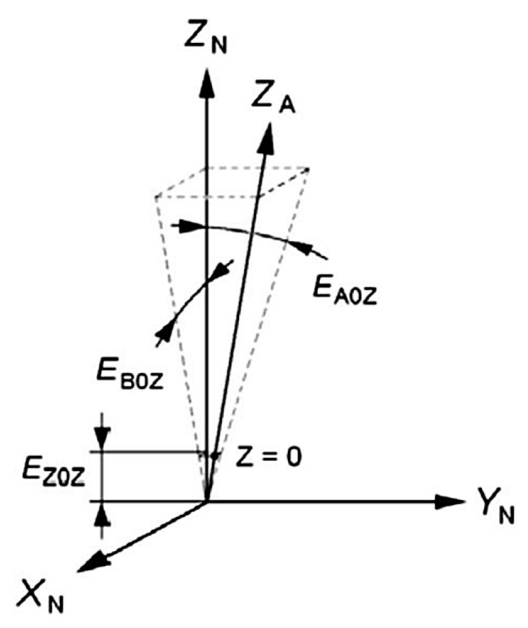

Fig. 3. Location errors of $\mathrm{Z}$ axis [15]

two squareness errors $\left(\mathrm{E}_{\mathrm{XOY}}, \mathrm{E}_{\mathrm{YOZ}}\right)$. The rotational axis of $\mathrm{A}^{\prime}$-axis and $\mathrm{B}$-axis must be parallel to the ideal motion direction of $\mathrm{Y}$-axis and $\mathrm{Z}$-axis, respectively; hence B-axis has two squareness errors $\left(\mathrm{E}_{\mathrm{X}(\mathrm{OY}) \mathrm{B}}, \mathrm{E}_{\mathrm{Z}(\mathrm{OY}) \mathrm{B}}\right)$, and $\mathrm{A}^{\prime}$-axis has two squareness errors $\left(\mathrm{E}_{\mathrm{X}(\mathrm{OZ}) \mathrm{A}^{\prime}}, \mathrm{E}_{\mathrm{Y}(\mathrm{OZ}) \mathrm{A}^{\mathrm{A}}}\right)$.

\section{Volumetric error modeling}

Volumetric error modeling of a machine tool aims to develop an error model that comprises all geometric error components into a three-dimensional error map at the cutting point as it moves in the work space. Rigid body kinematics and HTM are used for volumetric error modeling in this paper. There are eight rigid bodies in the fiveaxis machine tool, with kinematic chain diagram shown in Figure 4 machine bed chosen as the zero-order body. Each rigid body is represented by a number, e.g., "1" represents $\mathrm{X}$-axis. There 
are two structural loops; one is from machine bed to work piece, and the other is from machine bed to cutting tool, and are represented by "work piece structural loop" and "cutting tool structural loop," respectively, in this study. The transformation matrix between rigid body q and the adjacent low-order rigid body $\mathrm{p}$ is described as:

$$
{ }_{\mathrm{q}}^{\mathrm{p}}={ }_{\mathrm{q}} \mathrm{p}_{\mathrm{PT}} \cdot \mathrm{p}_{\mathrm{q}} \mathrm{T}_{\mathrm{PET}} \cdot{ }_{\mathrm{q}} \mathrm{p}_{\mathrm{MTM}} \cdot{ }_{\mathrm{q}} \mathrm{T}_{\mathrm{MTE}}=(1)
$$

Where ${ }_{\mathrm{q}} \mathrm{T}_{\mathrm{PT}},{ }_{\mathrm{q}} \mathrm{T}_{\mathrm{PET}},{ }_{\mathrm{q}} \mathrm{T}_{\mathrm{MTM}}$ and ${ }_{\mathrm{q}} \mathrm{p}_{\mathrm{MTE}}$ are position transformation matrix, position error transformation matrix, motion transformation matrix, and motion error transformation matrix of body q relative to body $\mathrm{p}$.

Based on Eq. (1), the transformation matrix between bodies in the work piece structural loop and cutting tool structural loop can be obtained as:

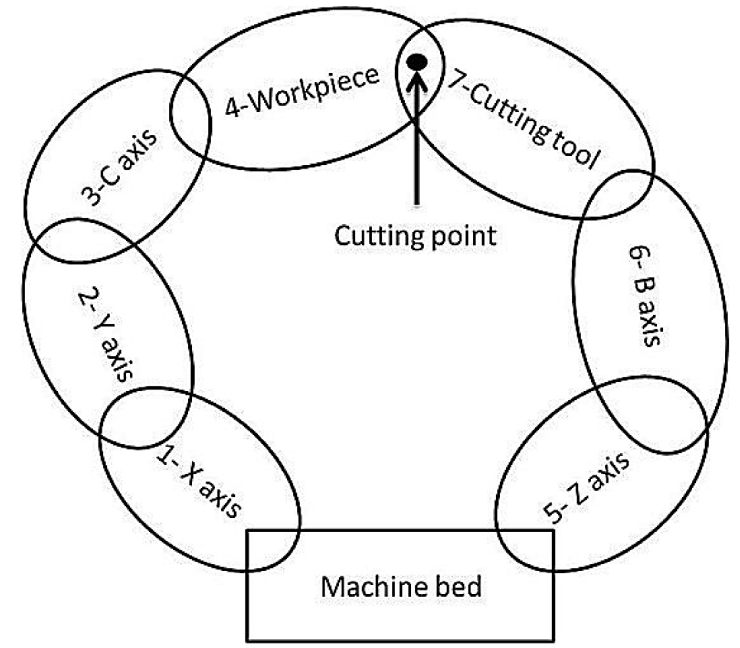

Fig. 4. Kinematic chain diagram of five-axis machine tool

$$
\begin{aligned}
& { }_{1}^{0} \mathrm{~T}_{\mathrm{p}}={ }_{1}^{0} \mathrm{~T} \mathrm{p} \cdot{ }_{1}^{0} \mathrm{~T} \mathrm{p} \cdot{ }_{1}^{0} \mathrm{~T} \cdot{ }_{1}^{0} \mathrm{~T}_{\mathrm{p}}=(2) \\
& {\left[\begin{array}{cccc}
1 & 0 & 0 & \mathrm{P}_{1 X} \\
0 & 0 & 1 & \mathrm{P}_{1 \mathrm{Y}} \\
0 & 0 & 0 & \mathrm{P}_{1 \mathrm{Z}} \\
0 & 0 & 0 & 1
\end{array}\right] \mathrm{I}_{4 \times 4}\left[\begin{array}{cccc}
1 & 0 & 0 & \mathrm{x} \\
0 & 1 & 0 & 0 \\
0 & 0 & 1 & 0 \\
0 & 0 & 0 & 1
\end{array}\right]\left[\begin{array}{cccc}
1 & -\mathrm{e}_{\mathrm{CX}} & \mathrm{e}_{\mathrm{BX}} & \mathrm{e}_{\mathrm{XX}} \\
\mathrm{e}_{\mathrm{CX}} & 1 & -\mathrm{e}_{\mathrm{AX}} & \mathrm{e}_{\mathrm{YX}} \\
-\mathrm{e}_{\mathrm{BX}} & \mathrm{e}_{\mathrm{AX}} & 1 & \mathrm{e}_{\mathrm{ZX}} \\
0 & 0 & 0 & 1
\end{array}\right]} \\
& { }_{2}^{1} \mathrm{~T}_{\mathrm{p}}={ }_{2}^{1} \mathrm{~T}_{\mathrm{p}} \cdot{ }_{2}^{1} \mathrm{~T}_{\mathrm{p}} \cdot{ }_{2}^{1} \mathrm{~T}_{\mathrm{p}} \cdot{ }_{2}^{1} \mathrm{~T}_{\mathrm{p}}=\text { (3) } \\
& {\left[\begin{array}{cccc}
1 & 0 & 0 & \mathrm{P}_{2 \mathrm{X}} \\
0 & 0 & 1 & \mathrm{P}_{2 \mathrm{Y}} \\
0 & 0 & 0 & \mathrm{P}_{2 \mathrm{Z}} \\
0 & 0 & 0 & 1
\end{array}\right]\left[\begin{array}{cccc}
1 & -\mathrm{E}_{\mathrm{XOY}} & 0 & 0 \\
\mathrm{E}_{\mathrm{XOY}} & 1 & -\mathrm{E}_{\mathrm{YOZ}} & 0 \\
0 & \mathrm{E}_{\mathrm{YOZ}} & 1 & 0 \\
0 & 0 & 0 & 1
\end{array}\right]\left[\begin{array}{llll}
1 & 0 & 0 & 0 \\
0 & 1 & 0 & \mathrm{Y} \\
0 & 0 & 1 & 0 \\
0 & 0 & 0 & 1
\end{array}\right]\left[\begin{array}{cccc}
1 & -\mathrm{e}_{\mathrm{CY}} & \mathrm{e}_{\mathrm{BY}} & \mathrm{e}_{\mathrm{XY}} \\
\mathrm{e}_{\mathrm{CY}} & 1 & -\mathrm{e}_{\mathrm{AY}} & \mathrm{e}_{\mathrm{YY}} \\
-\mathrm{e}_{\mathrm{BY}} & \mathrm{e}_{\mathrm{AY}} & 1 & \mathrm{e}_{\mathrm{ZY}} \\
0 & 0 & 0 & 1
\end{array}\right]} \\
& { }_{3}^{2} \mathrm{~T}_{\mathrm{p}}={ }_{3}^{2} \mathrm{~T}_{\mathrm{p}} \cdot{ }_{3}^{2} \mathrm{~T}_{\mathrm{p}} \cdot{ }_{3}^{2} \mathrm{~T} \cdot{ }_{3}^{2} \mathrm{~T}_{\mathrm{p}}=(4) \\
& {\left[\begin{array}{llll}
1 & 0 & 0 & \mathrm{P}_{3 \mathrm{X}} \\
0 & 0 & 1 & \mathrm{P}_{3 \mathrm{Y}} \\
0 & 0 & 0 & \mathrm{P}_{3 \mathrm{Z}} \\
0 & 0 & 0 & 1
\end{array}\right]\left[\begin{array}{ccccc}
1 & 0 & \mathrm{E}_{\mathrm{X}(\mathrm{OZZC})} & 0 \\
0 & 1 & -\mathrm{E}_{\mathrm{Y}(\mathrm{OZ}) \mathrm{C}} & 0 \\
-\mathrm{E}_{\mathrm{X}(\mathrm{OZ}) \mathrm{C}} & \mathrm{E}_{\mathrm{Y}(\mathrm{OZ}) \mathrm{C}} & 1 & 0 \\
0 & 0 & 0 & 1
\end{array}\right]\left[\begin{array}{cccc}
\cos \beta & -\sin \beta & 0 & 0 \\
\sin \beta & \cos \beta & 0 & 0 \\
0 & 0 & 1 & 0 \\
0 & 0 & 0 & 1
\end{array}\right]\left[\begin{array}{cccc}
1 & -\mathrm{e}_{\mathrm{CC}}(\beta) & \mathrm{e}_{\mathrm{BC}}(\beta) & \mathrm{e}_{\mathrm{XC}}(\beta) \\
\mathrm{e}_{\mathrm{CC}}(\beta) & 1 & -\mathrm{e}_{\mathrm{AC}}(\beta) & \mathrm{e}_{\mathrm{YC}}(\beta) \\
-\mathrm{e}_{\mathrm{BC}}(\beta) & \mathrm{e}_{\mathrm{AC}}(\beta) & 1 & \mathrm{e}_{\mathrm{ZC}}(\beta) \\
0 & 0 & 0 & 1
\end{array}\right]} \\
& { }_{4}^{3} \mathrm{~T}_{\mathrm{p}}={ }_{4}^{3} \mathrm{~T} \cdot{ }_{4}^{3} \mathrm{~T}_{\mathrm{p}} \cdot{ }_{4}^{3} \mathrm{~T} \cdot{ }_{4}^{3} \mathrm{~T}_{\mathrm{p}}=\left[\begin{array}{cccc}
1 & 0 & 0 & \mathrm{P}_{\mathrm{wx}} \\
0 & 0 & 1 & \mathrm{P}_{\mathrm{wy}} \\
0 & 0 & 0 & \mathrm{P}_{\mathrm{wz}} \\
0 & 0 & 0 & 1
\end{array}\right] \\
& { }_{5}^{0} \mathrm{~T}_{\mathrm{p}}={ }_{5}^{0} \mathrm{~T} \mathrm{p} \cdot{ }_{5}^{0} \mathrm{~T}_{\mathrm{p}} \cdot{ }_{5}^{0} \mathrm{~T}_{\mathrm{p}} \cdot{ }_{5}^{0} \mathrm{~T}_{\mathrm{p}}=(5) \\
& {\left[\begin{array}{cccc}
1 & 0 & 0 & \mathrm{P}_{5 \mathrm{X}} \\
0 & 0 & 1 & \mathrm{P}_{5 \mathrm{Y}} \\
0 & 0 & 0 & \mathrm{P}_{5 \mathrm{Z}} \\
0 & 0 & 0 & 1
\end{array}\right]\left[\begin{array}{cccc}
1 & 0 & \mathrm{E}_{\mathrm{XOZ}} & 0 \\
0 & 1 & 0 & 0 \\
-\mathrm{E}_{\mathrm{XOZ}} & 0 & 1 & 0 \\
0 & 0 & 0 & 1
\end{array}\right]\left[\begin{array}{llll}
1 & 0 & 0 & 0 \\
0 & 1 & 0 & 0 \\
0 & 0 & 1 & \mathrm{z} \\
0 & 0 & 0 & 1
\end{array}\right]\left[\begin{array}{cccc}
1 & -\mathrm{e}_{\mathrm{CZ}} & \mathrm{e}_{\mathrm{BZ}} & \mathrm{e}_{\mathrm{XZ}} \\
\mathrm{e}_{\mathrm{CZ}} & 1 & -\mathrm{e}_{\mathrm{AZ}} & \mathrm{e}_{\mathrm{YZ}} \\
-\mathrm{e}_{\mathrm{BZ}} & \mathrm{e}_{\mathrm{AZ}} & 1 & \mathrm{e}_{\mathrm{ZZ}} \\
0 & 0 & 0 & 1
\end{array}\right]} \\
& { }_{6}^{5} \mathrm{~T} \mathrm{p}={ }_{6}^{5} \mathrm{~T} \cdot{ }_{6}^{5} \mathrm{~T} \mathrm{p} \cdot{ }_{6}^{5} \mathrm{~T} \cdot{ }_{6}^{5} \mathrm{~T}_{\mathrm{p}}=(6) \\
& {\left[\begin{array}{cccc}
1 & 0 & 0 & \mathrm{P}_{6 \mathrm{X}} \\
0 & 0 & 1 & \mathrm{P}_{6 \mathrm{Y}} \\
0 & 0 & 0 & \mathrm{P}_{6 \mathrm{Z}} \\
0 & 0 & 0 & 1
\end{array}\right]\left[\begin{array}{cccc}
1 & -\mathrm{E}_{\mathrm{X}(\mathrm{OY}) \mathrm{B}} & 0 & 0 \\
\mathrm{E}_{\mathrm{X}(\mathrm{OY}) \mathrm{B}} & 1 & -\mathrm{E}_{\mathrm{Z}(\mathrm{OY}) \mathrm{B}} & 0 \\
0 & \mathrm{E}_{\mathrm{Z}(\mathrm{OY}) \mathrm{B}} & 1 & 0 \\
0 & 0 & 0 & 1
\end{array}\right]} \\
& \times\left[\begin{array}{cccc}
\cos \alpha & 0 & \sin \alpha & 0 \\
-\sin \alpha & 0 & \cos \alpha & 0 \\
0 & 0 & 1 & 0 \\
0 & 0 & 0 & 1
\end{array}\right]\left[\begin{array}{cccc}
1 & -\mathrm{e}_{\mathrm{CA}}(\alpha) & \mathrm{e}_{\mathrm{BA}}(\alpha) & \mathrm{e}_{\mathrm{XA}}(\alpha) \\
\mathrm{e}_{\mathrm{CA}}(\alpha) & 1 & -\mathrm{e}_{\mathrm{AA}}(\alpha) & \mathrm{e}_{\mathrm{YA}}(\alpha) \\
-\mathrm{e}_{\mathrm{BA}}(\alpha) & \mathrm{e}_{\mathrm{AA}}(\alpha) & 1 & \mathrm{e}_{\mathrm{ZA}}(\alpha) \\
0 & 0 & 0 & 1
\end{array}\right] \\
& { }_{7}^{6} \mathrm{~T}_{\mathrm{p}}={ }_{7}^{6} \mathrm{~T} \cdot{ }_{7}^{6} \mathrm{~T} \cdot{ }_{7}^{6} \mathrm{~T}_{\mathrm{p}} \cdot{ }_{7}^{6} \mathrm{~T}_{\mathrm{p}}=\left[\begin{array}{cccc}
1 & 0 & 0 & \mathrm{P}_{\mathrm{tx}} \\
0 & 0 & 1 & \mathrm{P}_{\mathrm{ty}} \\
0 & 0 & 0 & \mathrm{P}_{\mathrm{tz}} \\
0 & 0 & 0 & 1
\end{array}\right] \text { (7) }
\end{aligned}
$$


Where $\mathrm{p}_{\mathrm{ix}}, \mathrm{p}_{\mathrm{iy}}$ and $\mathrm{p}_{\mathrm{iz}}(\mathrm{i}=1,2,3,5,6)$ are the position coordinates in each position transformation matrix between bodies. The work piece and cutting tool are fixed on the $\mathrm{A}^{\prime}$-axis and $\mathrm{B}$-axis, respectively, and is considered as no errors. $p_{w x}$, $\mathrm{p}_{\mathrm{wy}}$, and $\mathrm{p}_{\mathrm{wz}}$ are the relative position coordinates between the coordinate systems of the work piece and $\mathrm{A}^{\prime}$-axis. Similarly, $\mathrm{p}_{\mathrm{tx}}, \mathrm{p}_{\mathrm{ty}}$, and $\mathrm{p}_{\mathrm{tz}}$ are the relative position coordinates between the coordinate systems of the work piece and B-axis. The position coordinate vectors of the cutting point in the coordinate system of the work piece and cutting tool are $\mathrm{Pw}$ and $\mathrm{Pt}$, shown as:

$$
\begin{aligned}
& \mathrm{Pw}=\left[\begin{array}{lll}
\text { Pwx } & \text { Pwy } & \text { Pwz }
\end{array}\right] \\
& \mathrm{Pt}=\left[\begin{array}{lll}
\text { Ptx } & \text { Pty } & \text { Ptz }
\end{array}\right]
\end{aligned}
$$

The volumetric error vector Ev is shown as Eq. (11), which can be solved by Eq. (12).

$$
\mathrm{Ev}=\left[\begin{array}{lll}
\mathrm{Pvx} & \mathrm{P} v \mathrm{P} & \mathrm{P} z \mathrm{z}
\end{array}\right]
$$

Where $E_{v}$ is the volumetric error homogenous transformation matrix representing position and orientation errors between the cutting tool and work piece. The position vector component of $E_{V}$ represents the translations in the tool point's coordinate frame that must be made to the tool point in order to be at the proper location on the work piece.

$$
\begin{aligned}
& {\left[\begin{array}{ll}
\text { Ev } & 1
\end{array}\right]=[\text { Evx Evy Evz } 1]} \\
& { }_{7}^{0} \mathrm{~T}=\left[\begin{array}{ll}
\mathrm{P}_{\mathrm{t}} & 1
\end{array}\right]-{ }_{4}^{0} \mathrm{~T} \cdot\left[\begin{array}{ll}
\mathrm{P}_{\mathrm{w}} & 1
\end{array}\right]
\end{aligned}
$$

Where:

$$
\begin{aligned}
& { }_{4}^{0} \mathrm{~T}={ }_{1}^{0} \mathrm{~T}_{2}^{1} \mathrm{~T}_{3}^{2} \mathrm{~T}_{4}^{3} \mathrm{~T} \\
& { }_{7}^{0} \mathrm{~T}={ }_{5}^{0} \mathrm{~T}_{6}^{5} \mathrm{~T}_{7}^{6} \mathrm{~T}
\end{aligned}
$$

\section{Compensation strategy}

Generally, the volumetric error compensation works in two ways: the feedback interruption compensation and origin shift compensation [2, $12,22]$. The feedback interruption compensation works in such a way that the phase signal is inserted into the feedback loop of the servo system. This method is applicable to most CNC machine tools, however certain attention needs to be paid since the inserted signal can easily interfere with the machine feedback signal. At the same time, the origin shift compensation can avoid this problem by sending the compensation signal to the $\mathrm{CNC}$ unit. The CNC unit then controls the Program Logic Control (PLC) unit to initiate a shift in the zero position of axes under inspection. This online compensation method does not rely on the modification of the hardware but is only applicable to modern CNC machines. Nonetheless, current commercially available numerical controllers is only capable of dealing with a small proportion of errors [23-25]. Majority of the error compensation are realized by designing new software or modifying NC codes [2].

In this article, a new tool path have been generated. Due to errors, for a machine without compensation device, the actual position of the tool always deviates from the nominal position, and the actual position attained by the tool becomes equal to the sum of the nominal position and of the errors that occur at the nominal position. In this paper, the fundamental thought of compensation is to predict the error at the given nominal position and to eliminate the error from the nominal position before the nominal position is, in turn, converted into the motion commands (joint commands). Thereafter, the new command, termed the error-compensated trajectory $\mathrm{T}_{\mathrm{c}}$ is sent to the drive system. The error-compensated trajectory is defined as:

$$
\mathrm{Tc}=\mathrm{Ti}-\Delta(\mathrm{Ti})
$$

Where $\mathrm{Ti}$ is the initial trajectory; $\mathrm{T}_{\mathrm{c}}$ is the trajectory compensated position and is the error at the nominal trajectory. Consequently, if the tool is commanded to move to $T_{c}$, the actual position attained by the tool is given by:

$$
\mathrm{Ti}=\mathrm{Tc}+\Delta(\mathrm{Tc})
$$

Where is the error at the error-compensated trajectory. Figure 5 demonstrates the whole concept of software compensation. In software compensation, the initial trajectory of tool entered compensation package and the compensation process was performed using a kinematic model. The compensated trajectory is overwritten. Finally the relevant code is generated.

\section{CASE STUDY}

\section{Identified geometric errors}

As earlier mentioned, error identification is the initial step in the error compensation strategy. After the error models are specified for all possible error sources, the next step is the measurement that should be conducted to determine the errors [7]. The measured results are capable of providing compensation parameters for the third step (error compensation). After characterization of the errors in the given error 


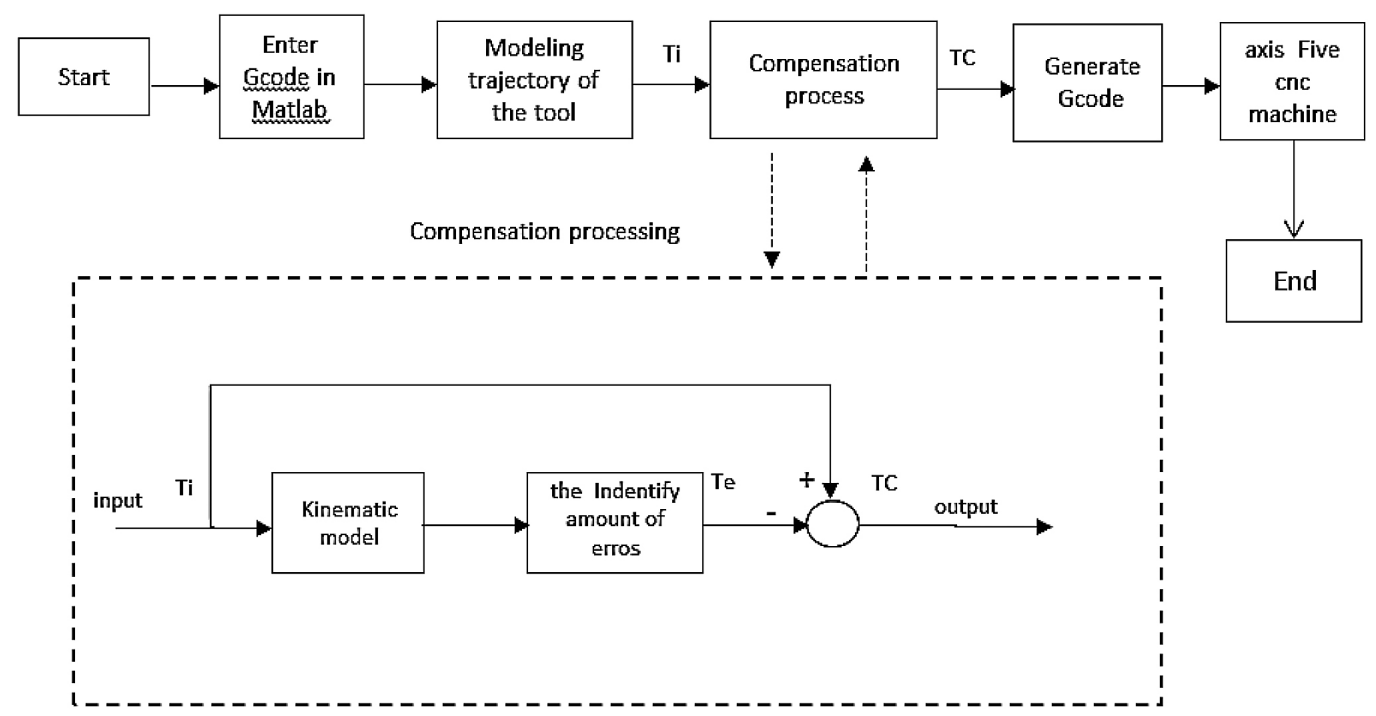

Fig. 5. Error compensation algorithm

models, error measurement strategies are developed based on the geometric characteristics. However, many errors may be superposed or overlapped in the course of their measurement. Thus it is difficult, sometimes impossible, to distinguish them in a single measuring process. To overcome this challenge, various methods using a wide variety of testing devices are proposed to deal with different errors. These measuring methods can be generally categorized into two approaches: direct measurements and indirect measurements [20]. The direct measurements refer to those measurements dealing with single errors. In this method, particular precision artefacts are used as measuring references; for instance straight edges, linear scales and step gauges $[20,26]$.

Dial gauges are used in conjunction with the above measuring references to indicate the values of errors. These methods have been used for decades and are included in national and international standards $[19,27]$. Nevertheless, they are still widely used due to their ease of use and simple structure. Another method is laser-based measurements which use a laser beam as the length measuring reference due to its great spatial coherence. An extensively used measuring device is the laser interferometer that enables the measurement of linear positioning errors of single axes. Its application has been expanded to enable the identification of all 21 geometric errors of three-axis machine tools by measuring the positioning errors along body diagonals or other specified directions [28, 29]. With different optics, errors such as angular errors, straightness errors and squareness errors of linear axes can be determined $[19,30]$. In measurement, indirect measuring techniques work with motions involving multiple axes to analyze the machine accuracy [21]. The indirect measurements require a specified test piece with particular geometries and shapes (e.g. a cone frustum) mounted on the machine under test, and is thereafter measured on a Coordinate Measuring Machine (CMM) [31]. The outcome of this method is influenced by a number of factors including the machining condition, accuracy of the CMM used, tool wear etc, and not just the geometric errors. Another indirect measurement is that of contour measurement, with multiple axes moving along a predefined path simultaneously [32]. Circular paths with two linear axes moving simultaneously [33], circular paths with two linear axes and one rotary axis moving simultaneously [34] and three-dimensional helix paths with three linear axes moving simultaneously $[35,36]$ are all possible trajectories for indirect measurements. Commercially available measuring equipment capable of contour measurement includes 3D ball plates [37], laser tracers [38], the R-test system and the DBB [39] etc. Below is a brief description of each of these.

From the aforementioned explanation in this study, the direct methods used for measurement of geometric error of five-axis $\mathrm{CNC}$ machine tools have been conducted according to [32]. Table 3 demonstrates the geometric error data measurement result. The standard test described here use artefact (e.g. a precision sphere or a straight edge) and a linear displacement sensor. 
Table 3. List of geometric errors

\begin{tabular}{|c|c|c|c|}
\hline Error & Value [ ] & Error $_{1}$ & Value [ ] \\
\hline$E_{X X}$ & 30.0 & $E_{Z 0 X}$ & 50.0 \\
\hline$E_{Y X}$ & 5.0 & $E_{Y 0 X}$ & 35.0 \\
\hline$E_{Z X}$ & 8.0 & $E_{A 0 X}$ & 16.0 \\
\hline$E_{A X}$ & 9.5 & $E_{B 0 X}$ & 42.0 \\
\hline$E_{B X}$ & 5.0 & $E_{C 0 X}$ & 22.0 \\
\hline$E_{C X}$ & 5.0 & $E_{X 0 Y}$ & 10.0 \\
\hline$E_{X Y}$ & 32.0 & $E_{Y 0 Y}$ & 8.0 \\
\hline$E_{Y Y}$ & 26.0 & $E_{Z 0 Y}$ & 12.5 \\
\hline$E_{Z Y}$ & 12.0 & $E_{A 0 Y}$ & 10.0 \\
\hline$E_{A Y}$ & 8.0 & $E_{B O Y}$ & 10.0 \\
\hline$E_{B Y}$ & 6.0 & $E_{C 0 Y}$ & 16.0 \\
\hline$E_{C Y}$ & 10.0 & $E_{X 0 Z}$ & 48.0 \\
\hline$E_{X Z}$ & 27.0 & $E_{Y 0 Z}$ & 36.0 \\
\hline$E_{Y Z}$ & 17.0 & $E_{Z 0 Z}$ & 29.0 \\
\hline$E_{Z Z}$ & 14.5 & $E_{A 0 Z}$ & 18.0 \\
\hline$E_{A Z}$ & 12.5 & $E_{B 0 Z}$ & 16.0 \\
\hline$E_{B Z}$ & 9.0 & $E_{C 0 Z}$ & 16.0 \\
\hline$E_{C Z}$ & 11.5 & - & - \\
\hline & & & \\
\hline
\end{tabular}

\section{EXPERIMENTAL RESULTS}

To verify the feasibility and effectiveness of the developed geometric error compensation method, an experiment was conducted on a fiveaxis machine tool. Its strokes are X450 Y310 Z500 (unit: $\mathrm{mm}$ ) for linear axis and $\mathrm{A}^{\prime}[0,360], \mathrm{B}$ $[-90,+90]$ (unit: deg) for rotation axis. Compensation experiments have been conducted using a five-axis machining center with the configuration controlled by a Heidenhein iTNC530 CNC shown in Figure 1. The steel alloy work piece was clamped on the rotary table of a five-axis machine tool. Summary of the process parameters of the test piece investigated has been shown in Table 4.

From the volumetric error model and software compensation in the preceding section, the experimental analysis of volumetric error in cutting point with regard to each error component can be made, and will be helpful in the improvement of machining accuracy. The work piece machining accuracy is guaranteed due to position of the cutting tool center point (TCP) in relation to the work piece. When kinematic errors are accurately identified enabling the error in the tool position and orientation to be estimated using the kinematic model, then their equivalent tool path in work piece coordinate system can be calculated using Eq. 10. Error compensation can be ap-
Table 4. Summary of the used process parameters of the test piece

\begin{tabular}{|l|l|c|}
\hline \multicolumn{1}{|c|}{ Tool } & \multicolumn{2}{c|}{$\begin{array}{c}\text { Diameter:14 mm } \\
\text { Number of teeth: 12 }\end{array}$} \\
\hline Spindle speed (s) & $\begin{array}{l}\text { rough } \\
\text { finish }\end{array}$ & $12000 \mathrm{rpm}$ \\
& rough & $0.4 \mathrm{~mm}$ \\
finish & $0.4 \mathrm{~mm}$ \\
\hline \multirow{2}{*}{ Feed per tooth } & rough & $1131 \mathrm{~mm} / \mathrm{min}$ \\
Resulting cutting speed & finish & $314 \mathrm{~mm} / \mathrm{min}$ \\
\hline Resulting contouring & rough & $1800 \mathrm{~mm} / \mathrm{min}$ \\
speed & finish & $500 \mathrm{~mm} / \mathrm{min}$ \\
\hline
\end{tabular}

plied to reach the ideal position and orientation by changing the reference trajectory; hence the following simple error compensation scheme is adopted to cancel the effect of kinematic errors.

Figure 6 reveals the compensated machining error trajectories for both bottom and top surfaces of the machined work pieces. From compared uncompensated trajectories, it is observed that by applying the error compensation scheme, error path trajectory is improved from 17.3 to $10.1 \mu \mathrm{m}$ at bottom and 19.5 to $11 \mu \mathrm{m}$ at top surfaces of the machined work pieces, thus leading to significant improvement in machining accuracy.

As previously mentioned, $\mathrm{E}_{\mathrm{V}}$ is the resultant volumetric error and $\mathrm{P}_{\mathrm{vx}}, \mathrm{P}_{\mathrm{vy}}$ and $\mathrm{P}_{\mathrm{vz}}$ are the volumetric error compensation components in $\mathrm{X}, \mathrm{Y}$ and $\mathrm{Z}$ directions respectively. $\mathrm{X}, \mathrm{Y}$ and $\mathrm{Z}$ axes volumetric error components are calculated using volumetric error model in Eqs. (8) - (10). Figure 7 includes the forward (F) and reverse (R) direction of the axis slide movement with respect to each axis volumetric error compensation. Only the measured parametric error data were used during computation of the volumetric error values.

If it is assumed that the geometric errors are accurately modeled and measured, all 37 errors can be compensated to improve the accuracy of the machine. In Figure 8, the error map result was graphically illustrated for surface comparatively before and after compensation. The maximum absolute deviation is about $0.009 \mathrm{~mm}$; and after applying the compensation algorithm, the maximum deviation is limited within $0.0008 \mathrm{~mm}$.

\section{CONCLUSIONS}

From the results, error compensation can be observed to effectively reduce machine tools error and enhance the machining accuracy compared with the test without compensation. 

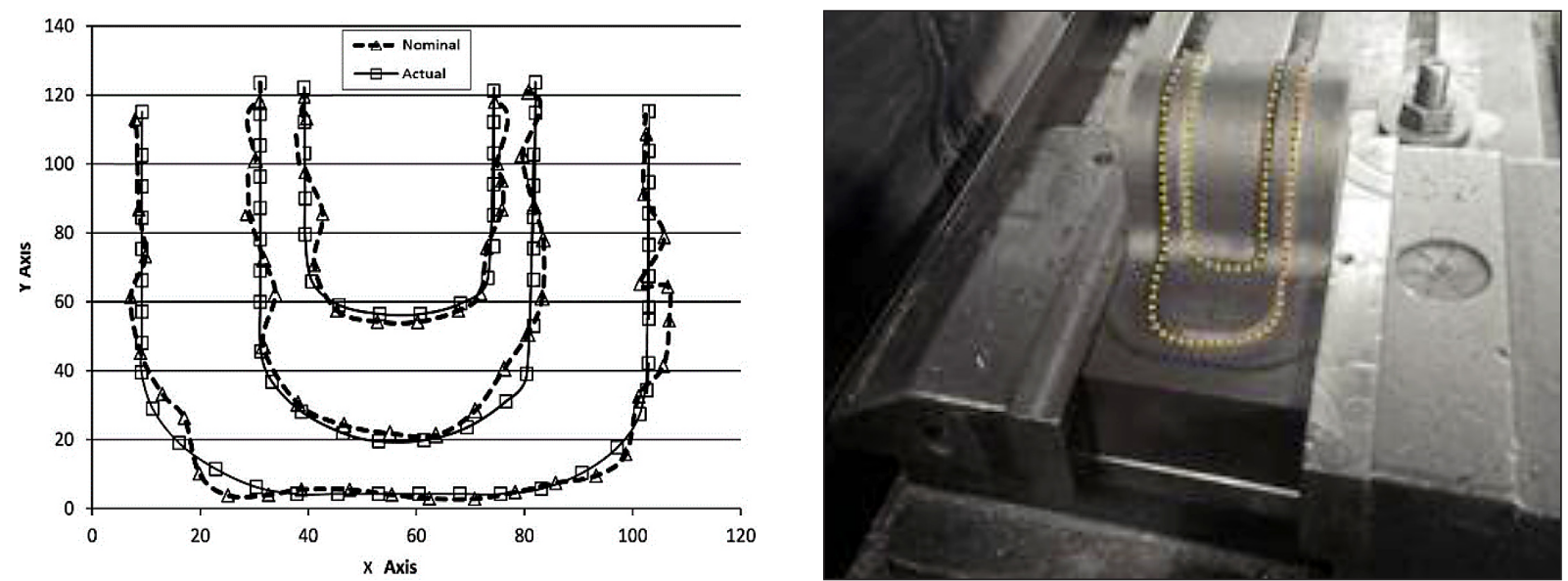

Fig. 6. Compensated and uncompensated trajectories for top and bottom surface
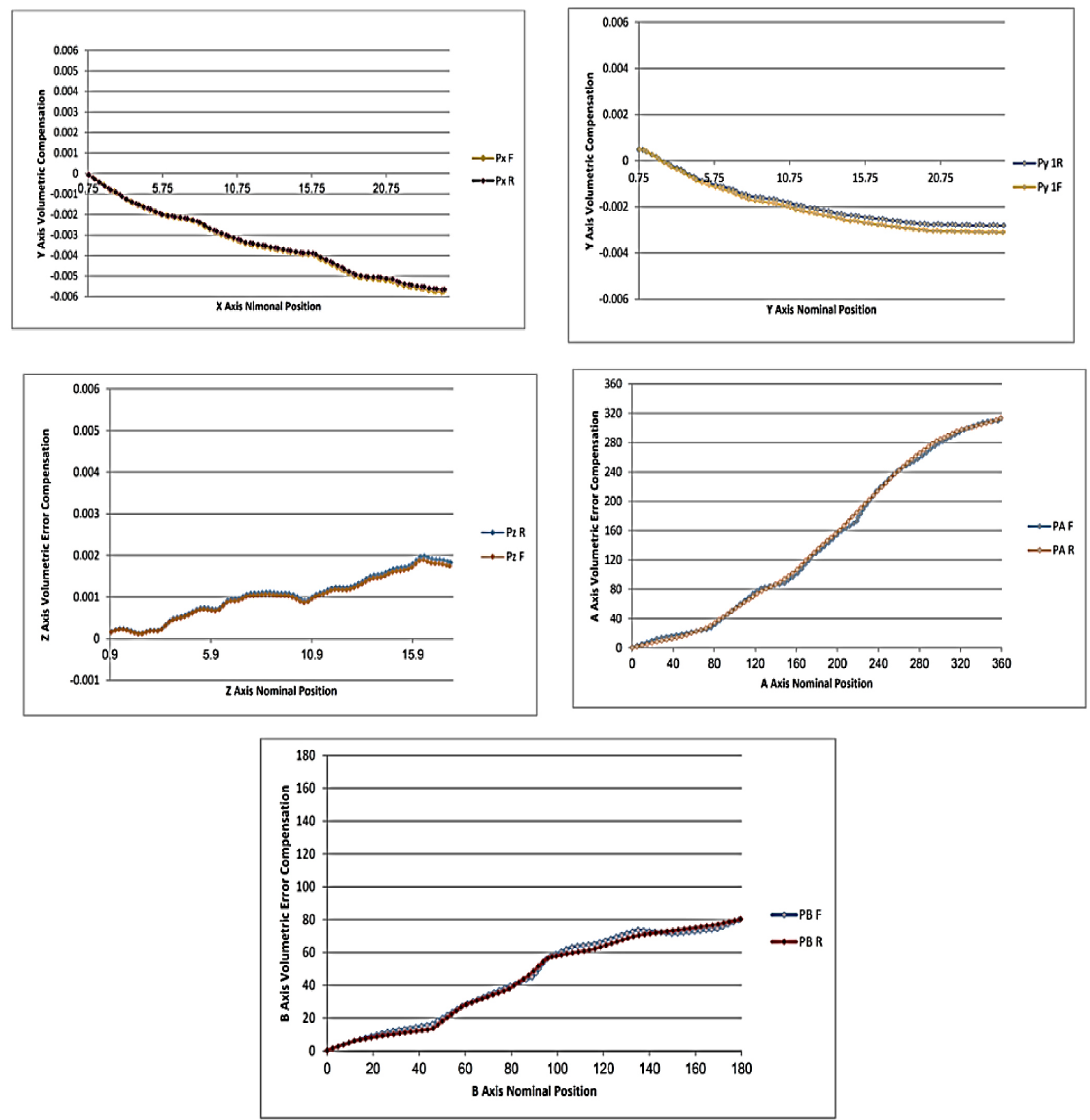

Fig. 7. X, Y, Z, A, B volumetric error compensation in forward and reverse direction 
a)

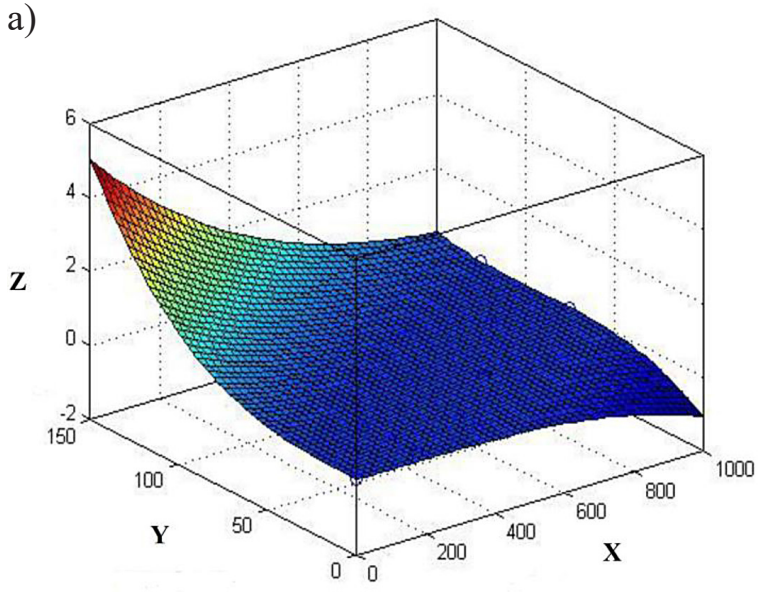

b)

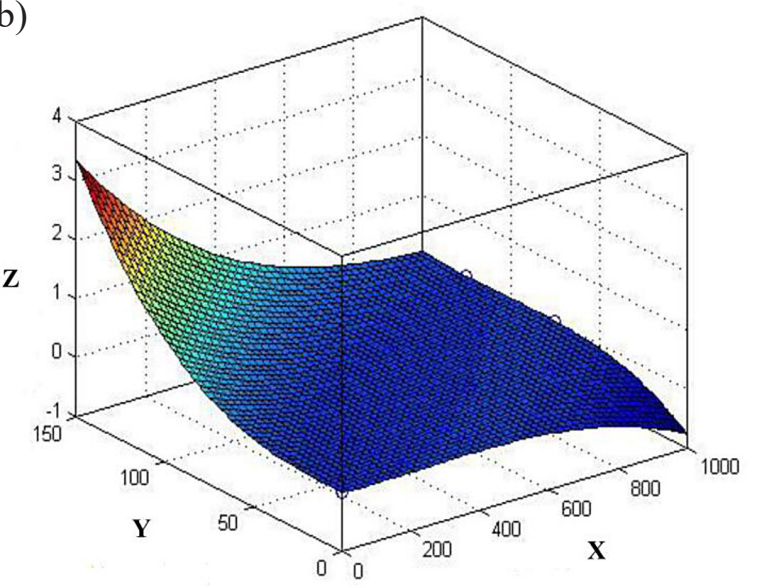

Fig. 8. Machining error map: a) without compensation, b) with compensation

To compensate for the errors, these have to be identified and measured. In terms of five-axis machine tools, fast, simple and reliable measurements are necessary to enable efficient error compensation. Current methods either take a long measuring time, or require considerably expensive equipment. To surmount the above drawbacks, research objectives including developing simple and fast measuring methods are proposed. Topologies of five-axis machine tools are explained and error identification and systematic geometric error sources are discussed in detail. 37 position-dependent and position-independent systematic geometric errors out of 52 potential errors of five-axis machine tools were identified and examined. This modeling technique is quite simple, comprehensive, robust, and easy to calculate, analyze and synthesize the geometric errors of five-axis machine tools for finding the volumetric workspace errors without unnecessary calculation and free from errors and mistakes.

Conversely, there are other error components that affect the performance of the machine tools, for instance, thermal errors, cutting force, tool wear etc., which needs to be corrected simultaneously. The existing research works are focused on correcting a small part of those errors. Thus further investigations need to be conducted on all of the error components, or at least most of them.

\section{Acknowledgements}

The authors gratefully acknowledge the financial support of the Ghatat Khodro Engineering Co. (No. 314598623).

\section{REFERENCES}

1. Kiridena V., Ferreira P.M. Mapping the effects of positioning errors on the volumetric accuracy of five-axis CNC machine tools. International Journal of Machine Tools and Manufacture, 1993, 33, 417-437.

2. Ramesh R., Mannan M.A., Poo A.N. Error compensation in machine tools - a review: Part I: Geometric, cutting-force induced and fixture-dependent errors. International Journal of Machine Tools and Manufacture, 2000, 40, 1235-1256.

3. Paul R.P.R.M.M., Programming, and Control (Artificial Intelligence). MIT Press, MA, USA 1982.

4. Khan A.W., Wuyi C. Systematic Geometric Error Modeling for Workspace Volumetric Calibration of a 5-axis Turbine Blade Grinding Machine. Chinese Journal of Aeronautics, 2010, 23, 604-615.

5. Denavit J., Hartenberg R.S. A kinematic notation for lower-pair mechanisms based on matrices. Trans of the ASME Journal of Applied Mechanics, 1955, 22, 215-221.

6. Okafor A.C, Ertekin Y.M. Derivation of machine tool error models and error compensation procedure for three axes vertical machining center using rigid body kinematics. International Journal of Machine Tools and Manufacture, 2000, 40, 1199-1213.

7. Hsu Y.Y. Accuracy test and geometric errors compensation. Hsinchu, Taiwan National Tsing Hua University, 2002.

8. Srivastava A.K., Veldhuis S.C., Elbestawit M.A. Modelling geometric and thermal errors in a fiveaxis cnc machine tool. International Journal of Machine Tools and Manufacture, 1995, 35, 1321-1337.

9. Jha B.K., Kumar A. Analysis of geometric errors associated with five-axis machining centre in improving the quality of cam profile. International Journal of Machine Tools and Manufacture, 2003, 43, 629-636. 
10. Lei W.T, Hsu Y.Y. Accuracy test of five-axis CNC machine tool with $3 \mathrm{D}$ probe-ball. Part I: design and modeling. International Journal of Machine Tools and Manufacture, 2002, 42, 1153-1162.

11. Lin Y., Shen Y. Modelling of Five-Axis Machine Tool Metrology Models Using the Matrix Summation Approach. Int J Adv Manuf Technol., 2003, 21, 243-248.

12. Zhang H., Yang J., Zhang Y., Shen J., Wang C. Measurement and compensation for volumetric positioning errors of CNC machine tools considering thermal effect. Int J Adv Manuf Technol., 2011, $55,275-283$.

13. Lu Y., Islam M.N. A new approach to thermally induced volumetric error compensation. Int J Adv Manuf Technol., 2012, 62, 1071-1085.

14. Cui G., Lu Y., Li J., Gao D., Yao Y. Geometric error compensation software system for $\mathrm{CNC}$ machine tools based on $\mathrm{NC}$ program reconstructing. Int $\mathrm{J}$ Adv Manuf Technol., 2012, 63, 169-180.

15. Bohez E.L.J., Ariyajunya B., Sinlapeecheewa C., Shein T.M.M., Lap D.T., Belforte G., Systematic geometric rigid body error identification of 5-axis milling machines. Comput Aided Des., 2007, 39, 229-244.

16. Huang T., Whitehouse D.J., Chetwynd D.G. A Unified Error Model for Tolerance Design, Assembly and Error Compensation of 3-DOF Parallel Kinematic Machines with Parallelogram Struts. CIRP Annals Manufacturing Technology, 2002, 51, 297-301.

17. Hong C., Ibaraki S., Matsubara A. Influence of position-dependent geometric errors of rotary axes on a machining test of cone frustum by five-axis machine tools. Precision Engineering, 2011, 35, 1-11.

18. Lee R.S., Lin Y.H. Applying bidirectional kinematics to assembly error analysis for five-axis machine tools with general orthogonal configuration. Int J Adv Manuf Technol., 2012, 62, 1261-1272.

19. ISO 230-1. Test code for machine tools -- Part 1: Geometric accuracy of machines operating under no-load or quasi-static conditions, 2012.

20. Schwenke H., Knapp W., Haitjema H., Weckenmann A., Schmitt R., Delbressine F. Geometric error measurement and compensation of machines-An update. CIRP Annals - Manufacturing Technology, 2008, 57, 660-675.

21. Yan Jiangyun L.B., Zhang Tao. The compensation technique of principal axis thermal deformation based on HEIDENHAIN NC system. Manufacturing Technology and Machine Tool, 2012, 8.

22. Wang B. The study on thermal errors compensation of NC machine tools, 2010.

23. Siemens Energy and Automation Inc. Siemens Sinumerik 840 Series User's manual. Siemens I, USA 1996.
24. Johannes Heidenhain GmbH. Heidenhain TNC 426/430 User's manual conversational programming. Dr. Johannes Heidenhain GmbH T., Germany, 1999.

25. FANUC America Corporation. FANUC Series 35iModel B. FANUC I, USA, 2013.

26. Sartori S.Z, G.X. Geometric error measurement and compensation of machines. Annals of the CIRP 44(2), 1995, 599-609.

27. ASME B5.54. Methods for performance evaluation of computer numerically controlled machining centers. American Society of Mechanical Engineers NY, US, 2005.

28. Yang F.D., Z. Yang, J. Hong, M. Review on geometric error measurement of machine tools. Manufacturing Technology and Machine Tool, 2012(3), 2013, 19-23.

29. Zhang Z., Hu H. A general strategy for geometric error identification of multi-axis machine tools based on point measurement. Int $\mathrm{J}$ Adv Manuf Technol., 2013, 69, 1483-1497.

30. Automated Precision Inc. API XD laser brochure. API Inc. M, US, 2014.

31. Renishaw brochure: XR20-W rotary calibrator. Renishaw plc. G.

32. ISO 10791-1 I. Test conditions for machining centres -Part 1: Geometric tests for machines with horizontal spindle, 2015.

33. Renishaw plc. QC20-W wireless ballbar system description and specifications. Renishaw plc. G, UK, 2014.

34. Tsutsumi M., Saito A. Identification and compensation of systematic deviations particular to 5-axis machining centers. International Journal of Machine Tools and Manufacture, 2003, 43, 771-780.

35. Yang S.H., Kim K.H., Park Y.K., Lee S.G. Error analysis and compensation for the volumetric errors of a vertical machining centre using a hemispherical helix ball bar test. Int J Adv Manuf Technol., 2004, 23, 495-500.

36. Yang S-H., Kim K-H., Park Y.K. Measurement of spindle thermal errors in machine tool using hemispherical ball bar test. International Journal of Machine Tools and Manufacture, 2004, 44, 333-340.

37. Bringmann B., Küng A., Knapp W. A Measuring Artefact for true 3D Machine Testing and Calibration. CIRP Annals - Manufacturing Technology, 2005, 54, 471-474.

38. Schwenke H., Franke M., Hannaford J., Kunzmann $\mathrm{H}$. Error mapping of CMMs and machine tools by a single tracking interferometer. CIRP Annals Manufacturing Technology, 2005, 54, 475-478.

39. Weikert S. R-Test, a New Device for Accuracy Measurements on Five Axis Machine Tools. CIRP Annals - Manufacturing Technology, 2004, 53, 429-432. 